\title{
Mental health need amongst the intellectually disabled
}

\author{
B. D. Kelly
}

Received: 30 January 2011/Accepted: 13 February 2011/Published online: 24 April 2013

(C) Royal Academy of Medicine in Ireland 2013

\section{Dear Editor,}

The College of Psychiatry of Ireland concludes that "the provision of mental health and forensic mental health services for people with an intellectual disability, as set out in $A$ Vision for Change, requires immediate prioritisation" [1].

The issue is both important and long-standing.

In 1907, Dr Conolly Norman, outspoken and progressive medical superintendent at the Richmond District Asylum (now St. Brendan's Hospital, Dublin) lamented the absence of services for individuals with intellectual disability: "It is neither wise nor humane to neglect [the intellectually disabled] as they are neglected in this country" $[2,3]$.

\section{References}

1. Barry S, Crumlish N, Leonard P (2011) Excluded, expelled and exported: the citizens we've ignored and those we've exiled. College of Psychiatry of Ireland, Dublin

2. Richmond District Asylum Joint Committee (1907) Richmond District Asylum Joint Committee minutes. Richmond Asylum, Dublin

3. Kelly BD (2008) Learning disability and forensic mental healthcare in nineteenth-century Ireland. Ir J Psychol Med 25(3):116118
B. D. Kelly $(\bowtie)$

Department of Adult Psychiatry, Mater Misericordiae University

Hospital, University College Dublin, 62/63 Eccles Street,

Dublin 7, Ireland

e-mail: brendankelly35@gmail.com 